Gut, 1968, 9, 667-671

\title{
Psychological factors, operative procedures, and results of surgery for duodenal ulcer
}

\author{
A. I. M. GLEN ${ }^{1}$ AND ALAN G. COX \\ From the Department of Surgery, University of Glasgow
}

The long-term outcome of surgery for peptic ulcer has been the subject of many investigations, most of which relate to recurrent ulceration, alimentary symptoms, and impaired nutrition. The study reported in this paper is concerned with the effect of psychological factors on the outcome of surgery. Surgeons have always recognized the importance of selecting the right patient for surgery ('do-ers and non-do-ers') but the significance of these factors has not been adequately assessed.

The hypothesis tested in this investigation was that patients with bad postoperative results have abnormal personality and mood disorders before surgery.

Standard techniques to measure certain aspects of personality and mood were used to evaluate the outcome of two different operations, to explore the relationship between symptomatic results and these psychological factors, and to seek the existence of psychological changes before operation and their effect after surgery.

\section{CLINICAL MATERIAL}

POSTOPERATIVE PATIENTS The basis of the study was a long-term, prospective investigation started in 1954 in the Peptic Ulcer Clinic at the Western Infirmary, Glasgow. In this project, male patients coming to elective surgery for chronic duodenal ulcer were treated either by a Polya partial gastrectomy or by total vagotomy with gastrojejunostomy. The choice was made randomly only after the surgeon had completed his preliminary laparotomy and satisfied himself that he could carry out either operation with complete safety.

The present study includes only those patients who had been operated on at least eight years previously. The percentage follow-up of the total number of available patients was 82 in the Polya group (56 patients) and 84 in the vagotomy group (51 patients). Personality testing was carried out in 39 patients in the Polya group and in 37 patients from the vagotomy group, all selected

'Present address: M.R.C. Clinical Psychiatry Research Unit, Graylingwell Hospital, Chichester, Sussex.

2Present address: Department of Surgery, Royal Postgraduate Medical School, Hammersmith Hospital, London. randomly. These operated patients are subsequently referred to in the text as group A patients.

PREOPERATIVE PATIENTS The group A patients were compared with unoperated ulcer patients and with the standard control values for the tests.

The unoperated patients were an unselected series of chronic duodenal ulcer patients who presented for preliminary investigation during the follow-up of group A. Seventy-eight male and female patients in all were studied, but in order to make a comparison with the group A patients (all males), the male unoperated patients were examined separately and are subsequently referred to in the test as group B. Sixty-six of the total preoperative patients (males and females) were followed up immediately after surgery to assess the physiological completeness of vagotomy and to see if, using insulin tests, secretion of acid related to preoperative personality. These are subsequently referred to as group $\mathrm{C}$ patients.

\section{METHOD OF STUDY}

Personality was measured by means of questionnaires which were given to the patients with the explanation that we wished to investigate certain aspects of personality in their condition. Two questionnaires which have been standardized for large groups of normal individuals were used.

EYSENCK PERSONALITY INVENTORY (EPI forms A and B) The EPI (Eysenck and Eysenck, 1964) is a development of the Maudsley personality inventory (Eysenck, 1959) and gives a measure both of neuroticism and of extraversionintraversion. Each EPI form comprises 57 statements relating to mode of behaviour, thinking etc. The patient indicates whether the statement does or does not apply to himself by making a cross in appropriate spaces beside each statement. The completed form gives a separate score for neuroticism and extraversion-intraversion. In this investigation the mean score for forms $\mathrm{A}$ and $\mathrm{B}$ was used.

MINNESOTA MULTIPHASIC PERSONALITY INVENTORY (MMPI) The MMPI (Hathaway and McKinley, 1951) is used to measure aspects of personality and mood and is usually completed by the patients in a standard form comprising 550 questions. For the present investigation the 56 statements describing mood were used. As with the EPI, the 
patients were asked to indicate whether each statement was true or false as applied to himself, and the form was checked to arrive at a depression score (MMPID).

Insulin tests of gastric acid secretion were carried out after vagotomy in 66 of the ulcer patients who had completed the EPI, and in 31 who had completed the MMPI before operation (group C). The insulin test is used to evaluate the completeness of surgical vagotomy but interpretation of the results has been the subject of recent controversy (Johnston, Goligher, and Duthie, 1966). There is general agreement that a complete vagotomy has been carried out if the acid concentration rises less than $20 \mathrm{~m}$-equiv/l. above basal levels within two hours of an intravenous injection of 20 units of soluble insulin. This result is described as a 'negative response'. A rise of 20 m-equiv/l. or more within one hour of the insulin is described as a 'positive response' and indicates an incomplete section of the vagus at operation. The suggestion has, however, been made that the vagotomy is less effective in terms of a higher incidence of recurrent ulcer if such a response occurs more than one hour after the insulin injection (Hollander, 1948). Such results are now described as 'late positive' and are the subject of considerable surgical and physiological interest.

CLINICAL ASSESSMENT Patients were carefully interviewed by the surgeon to evaluate the result of the operations. On the basis of symptoms and their severity, the patients were placed in one of the following grades:

Grade I No alimentary symptoms.

Grade II Mild alimentary symptoms which do not interfere with enjoyment of life or capacity for work.

Grade III Moderate alimentary symptoms which do interfere with enjoyment of life and capacity for work and are effectively diminished by simple treatment.

Grade IV Severe alimentary symptoms which interfere with life and work and do not respond to treatment.

The patients were graded in this manner before the results of the personality tests were known.

\section{RESULTS}

In analysing our findings, we studied the hypothesis that the psychological measures in the ulcer patients would be the same before and eight years after gastric surgery and that bad results from surgery would be related more to psychological deviations than to the nature of the operation.

The results are presented in three sections. First, a comparison of neuroticism, extraversion-intraversion, and of depression is made between the findings in groups A and B patients (duodenal ulcer patients eight or more years after surgery, and duodenal ulcer patients awaiting surgery). Second, the findings in group A (gastrectomy and vagotomy) patients are compared for personality and mood disturbance and analysed according to the symptomatic result of the operation. Third, the relationship between preoperative personality and postoperative insulin testing in group $\mathrm{C}$ is examined.

OPERATED (GROUP A) AND UNOPERATED (GROUP B) PATIENTS COMPARED Table I shows the values for neuroticism, extraversion-intraversion, and depression in the group A and B patients for all unoperated patients (males and females) and for standard norms for the tests. The mean values of EPI scores for neuroticism and extraversionintraversion in group A (operated patients) were marginally lower than in the group B patients, but when a two-tailed test of significance between the means was applied, these differences proved not to be significant. The two groups were closely matched with respect to age (group A mean 48.9, SD 8.5; group B mean 43.9, SD 9.6) so that our hypothesis was supported.

Since the standards provided for the EPI give normal ranges only for combined male and female groups it was necessary to refer to the unoperated patients for comparison. The figures can only be a rough guide and are not considered essential to the investigation, but the ulcer patients proved signi-

TABLE I

SCORES FOR NEUROTICISM, EXTRAVERSION-INTRAVERSION (OPERATED) AND DEPRESSION IN GROUP A AND GROUP B (UNOPERATED) ULCER PATIENTS WITH THE NORMAL VALUES FOR THE TESTS FOR COMPARISON

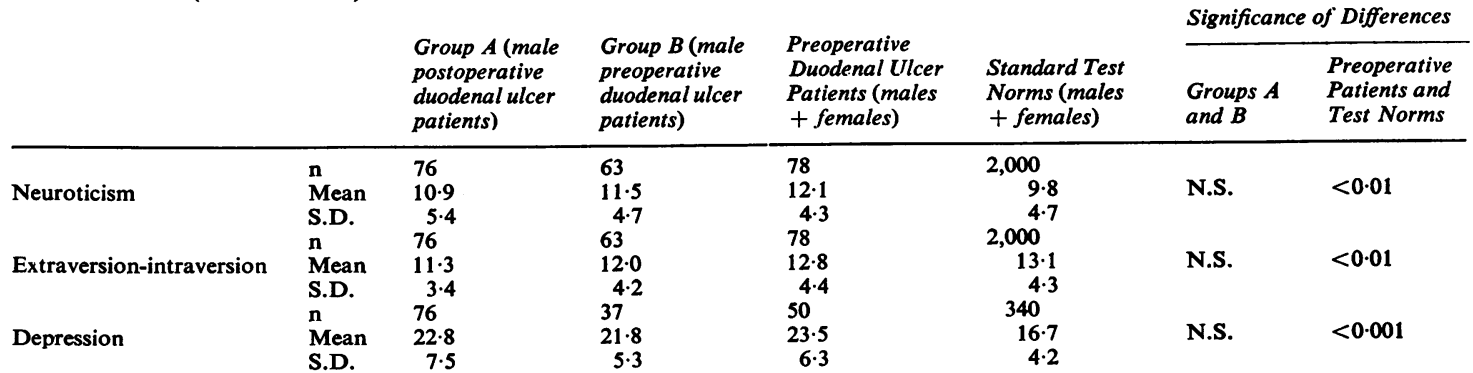

The normal values for the EPI tests A and B are those given by Eysenck and Eysenck (1964) and for the MMPI by Hathaway and McKinley (1951). 
ficantly more neurotic and less extraverted than the normal population standard.

Similar results were found for depression. The numbers for this group were fewer, because the depression questionnaire was only administered in the latter part of the investigation. Group A patients were fcund to be marginally more depressed than the group B patients, but not significantly so, and when the male and female unoperated group were compared with the standard normal population values, the ulcer patients were found to be much more depressed. The age matching for the smaller number of patients given the depression questionnaire was less satisfactory (group A patients as before $48 \cdot 9$, SD $8 \cdot 5$, group B patients $38 \cdot 6$, SD $11 \cdot 8$ ) but considering the wide scatter of ages and the fact that both ulcer groups were much more depressed than the standard values for the normal population indicated we did not consider that the age discrepancy invalidated the result.

Further analysis of group $A$ These were patients studied at least eight years after gastric surgery in order to see how outcome related to personality and to disturbance of mood.

Effect of the type of operation The two operated groups (randomly selected) closely resembled each other in respect of age, height, weight, and time since operation (Table II). When the psychological

\section{TABLE II}

SIMILARITY OF PATIENTS AFTER THE TWO DIFFERENT OPERATIONS

\begin{tabular}{|c|c|c|}
\hline & Mean Value \pm Sto & ird Deviation ${ }^{1}$ \\
\hline & $\begin{array}{l}\text { Vagotomy with } \\
\text { Gastrojejunostomy }\end{array}$ & $\begin{array}{l}\text { Polya } \\
\text { Gustrectomy }\end{array}$ \\
\hline $\begin{array}{l}\text { Age (yr) } \\
\text { Height }(\mathrm{cm}) \\
\text { Weight (kg) } \\
\text { Months since operation }\end{array}$ & $\begin{array}{r}4 \cdot \cdot 3 \pm 8 \cdot 4 \\
170 \cdot 1 \pm 6 \cdot 9 \\
62 \cdot 9 \pm 7 \cdot 2 \\
102 \cdot 4 \pm 17 \cdot 1\end{array}$ & $\begin{aligned} 49.8 & \pm 8.7 \\
169.0 & \pm 6.5 \\
61.1 & \pm 7.6 \\
104.7 & \pm 12.3\end{aligned}$ \\
\hline
\end{tabular}

${ }^{1}$ None of the differences approaches statistical significance.

factors eight years after operation were examined no significant difference in personality or in mood disturbance was found between patients treated by different operations. Using duration of symptoms in years before operation as an index of severity, this was found to be similar in both groups. Table III shows the results of an analysis of variance for each variable to test for differences between the two postoperative groups (39 patients treated by Polya gastrectomy and 37 patients by vagotomy and gastrojejunostomy). The mean values in the two groups are not significantly different. Since the variances were similar it was found convenient to examine further these patients as a single group.

TABLE III

EFFECT OF TYPE OF OPERATION

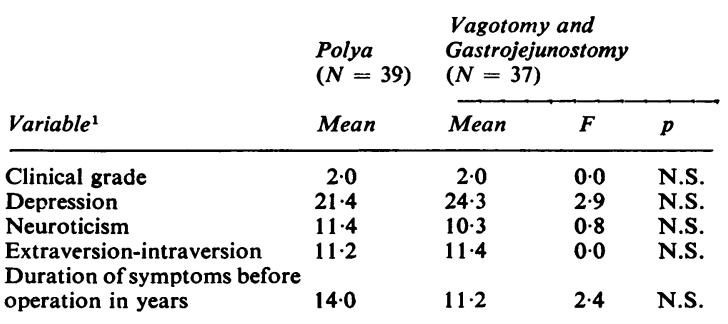

${ }^{1}$ Two-way analysis of variance for each variable shows no difference between groups for any variable.

RELATIONSHIPS BETWEEN THE VARIABLES Table IV shows the correlation matrix for the five variables. Although the coefficients of the correlation are low there is a relationship between clinical grading and both depression and personality (neuroticism and extraversion-intraversion), but no relation between preoperative chronicity and personality. Depression and neuroticism are positively correlated but not significantly.

Good results and bad results Tables V and VI show the relation between outcome and the psychological measures in more detail. The analysis of variance illustrates a significant relationship between personality and symptomatic outcome of operation. No relationship for chronicity of the disease (duration of symptoms in years) and personality was found. The scores for depression in the III and IV grades are particularly high.

TABLE IV

CORRELATION MATRIX FOR 76 POSTOPERATIVE DUODENAL ULCER PATIENTS

\begin{tabular}{|c|c|c|c|c|c|}
\hline & Grading & Neuroticism & $\begin{array}{l}\text { Extraversion- } \\
\text { intraversion }\end{array}$ & Depression & $\begin{array}{l}\text { Duration } \\
\text { Preoperative }\end{array}$ \\
\hline $\begin{array}{l}\text { Grading } \\
\text { Neuroticism } \\
\text { Extraversion-intraversion } \\
\text { Depression } \\
\text { Preoperative duration of symptoms }\end{array}$ & 1 & $\begin{array}{c}+0 \cdot 23^{1} \\
1\end{array}$ & $\begin{array}{c}-0.24^{1} \\
-0.20 \\
1\end{array}$ & $\begin{array}{l}+0.34^{1} \\
+0.26 \\
+0.08 \\
\quad 1\end{array}$ & $\begin{array}{l}+0.006 \\
+0.06 \\
-0.11 \\
-0.21 \\
\quad 1\end{array}$ \\
\hline
\end{tabular}


TABLE V

CLINICAL GRADES I + II COMPARED WITH GRADES III + IV

\begin{tabular}{|c|c|c|c|c|}
\hline Variable & $\begin{array}{l}\text { Grades } \\
I+I I\end{array}$ & $\begin{array}{l}\text { Grades } \\
\text { III }+I V\end{array}$ & $F$ & $p^{1}$ \\
\hline \multirow{4}{*}{$\begin{array}{l}\text { Depression } \\
\text { Neuroticism } \\
\text { Extraversion-intraversion } \\
\text { Duration of symptoms before } \\
\text { operation in years }\end{array}$} & & 28.4 & $14 \cdot 3$ & 0 \\
\hline & & 12 & & \\
\hline & 11.6 & 10.0 & $3 \cdot 2$ & N.S. \\
\hline & $13 \cdot 1$ & 11.0 & 0.9 & NS \\
\hline
\end{tabular}

${ }^{1}$ Two-way analysis of variance shows significant differences between groups only for depression.

TABLE VI

BAD RESULTS (GRADE IV) COMPARED WITH THE REST OF THE PATIENTS

\begin{tabular}{lllll} 
& $\begin{array}{c}\text { Grades } \\
I+I I\end{array}$ & \multicolumn{1}{l}{ Grade } & & \\
Variable & $+I I I$ & \multicolumn{1}{c}{ IV } & \multicolumn{1}{c}{$\boldsymbol{F}$} & \multicolumn{1}{c}{$p^{1}$} \\
\hline Depression & 21.7 & 30.8 & 13.0 & $<0.001$ \\
$\begin{array}{l}\text { Neuroticism } \\
\text { Extraversion-intraversion }\end{array}$ & 10.3 & 15.2 & 6.9 & $<0.01$ \\
$\begin{array}{l}\text { Duration of symptoms before } \\
\text { operation in years }\end{array}$ & 12.8 & 11.8 & 0.10 & N.S.
\end{tabular}

${ }^{1}$ Two-way analysis of variance shows significant differences for personality tests but no difference for severity as measured by duration of symptoms.

RELATIONSHIP BETWEEN POOR CLINICAL OUTCOME AND PERSONALITY The results in Section II suggest a relationship between poor clinical outcome of operation and personality. Although we have found no relation between personality and duration of ulcer symptoms before operation (Table IV), the view might still be taken that the results of these psychological tests merely reflect the patient's physical condition and are not causally related. While only a prospective study can provide a definite answer, some suggestion that a causal relationship between personality and symptomatic results of surgery holds is given in an examination of the immediate postoperative insulin test.

INSULIN TEST RESULTS IN GROUP C PATIENTS Sixty-six of the preoperative patients who had returned questionnaires for the Eysenck personality test and for the depression questionnaire underwent insulin testing within 14 days of surgical vagotomy. At this stage no assessment of the clinical result could be made, but it was found (Table VII) that differences in personality existed between those patients found to be insulin negative by Hollander's criteria and those found to have a late positive result. The late positive patients (a group thought to have a higher incidence of recurrent ulcer) were found to be more neurotic than the insulin-negative patients. Two patients with an early positive result were not included in the analysis since this category indicates incomplete section of the vagus at operation.
TABLE VII

INSULIN TESTS FOR COMPLETENESS OF VAGAL SECTION RELATED TO PREOPERATIVE PERSONALITY ASSESSMENT

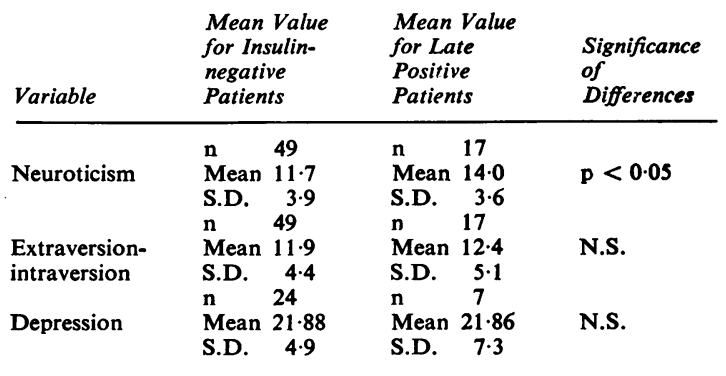

\section{DISCUSSION}

Many advances have been made in recent years in gastric physiology and in surgical treatment of duodenal ulcer. Yet there is still no framework upon which to base the total management of the ulcer patient. Why does one patient have intractable ulceration and another develop total remission of symptoms? Can the acid-secretion-mucosa-resistance equation so often quoted fully explain why one individual recovers completely and another has a recurrent ulcer or other alimentary symptoms?

As recently as 1964, Kessel and Munro, reviewing the status of psychosomatic theory and practice, felt compelled to say that although a wealth of observation and experiment had demonstrated that emotional factors influence the state of the gastric mucosa and the degree of acidity it had not yet been satisfactorily demonstrated that psychological factors were aetiologically associated with peptic ulcer. This view would be in keeping with that of Roth (1955).

Sainsbury (1960), using the Maudsley personality inventory and comparing a small group of peptic ulcer patients with non-psychosomatic controls, did not find significant differences in the ulcer group and psychosomatic outpatient controls. However, Kanter and Hazelton (1964), confining their studies to young duodenal ulcer outpatients and using inpatient nonpsychosomatic controls, found higher MPI scores for neuroticism and lower scores for extraversion in the ulcer patients.

In post-operative studies Sinclair-Gieben, Clark, and Dean (1962) found that duodenal ulcer patients with obsessional personality fared less well after surgery than did patients without obsessional traits. Studies using psychological factors as predictors of outcome following surgery have been reported by Thoroughman (1963) and Pascal, Thoroughman, Jarvis, and Jenkins (1966). In these studies, life history factors have been scored preoperatively using a deprivation scale devised specifically for 
ulcer patients and the scores obtained used to predict outcome at a three-year follow-up. Significant relationships between prediction and outcome have been reported by these workers.

Our findings, using the Eysenck personality inventory, resemble those of Kanter and Hazelton in that higher scores for neuroticism were obtained both before and after operation. The high scores for depression after surgery, and especially in those patients with a bad clinical result of surgery, are in keeping with the findings of Thoroughman and his colleagues using their deprivation scale, a high score for depression being equivalent to feelings of rejection and deprivation.

Our findings that the same proportion of psychological disturbance occurs in both operations are in keeping with those of Goligher, Pulvertaft, and Watkinson (1964) in which an equal number of unsatisfactory results were found regardless of operation.

As an index of severity of the original disease process, we used duration of symptoms preoperatively and this was not found to be related to personality deterioration. These findings are in keeping with those of Sainsbury in his study of medical outpatients.

Our results would suggest that the patients with bad postoperative results were those who also had abnormal personality before surgery. We have not yet had the opportunity of following up our preoperative patients over a suitable period of time to validate this suggestion, but it has been possible to show that certain patients with high scores for neuroticism show physiological changes (the insulin test) in the immediate postoperative period which are said to be associated with poor prognosis.

We feel that it is therefore of some interest that psychological factors were related to the insulin response. Further work is in progress to determine the predictive value of these psychological measures and also of physiological criteria of personality. Our findings are similar to those of Silverman, McGough, and Bogdonoff (1967) who suggest that hypothalamic mobilization produced by insulin is variable and that these differences have psychological parallels.

Operation for peptic ulcer is usually a successful procedure, but the results in an individual can occasionally be unexpectedly tragic. The development of objective and reliable methods for predicting these poor risk patients is essential. This study suggests that psychological as well as physiological methods are useful.

\section{SUMMARY}

In order to find out if personality traits (neuroticism and extraversion) and disturbance of mood (depression) were as important in determining the outcome following surgery for duodenal ulcer as was the type of operation, a comparison has been made between preoperative and postoperative patients using standard questionnaires.

Considering the symptomatic results of surgery, (1) a bad result occurred as often after gastrojejunostomy and vagotomy as after partial gastrectomy; (2) a bad result after surgery was associated with significant personality and mood disorder.

In a complementary study, preoperative patients were followed up immediately after surgery (all had vagotomy with a drainage procedure) to assess the physiological completeness of vagotomy using the insulin test. Patients with a late response of acid secretion following insulin were found to have a significantly higher score for neuroticism than those who did not secrete acid.

We are grateful to Professor A. W. Kay, Regius Professor of Surgery, University of Glasgow, for permission to study patients in his department, and to both Professor Kay and to Professor T. F. Rodger, Professor of Psychiatry, University of Glasgow, for their support and encouragement. A.I.M.G. was in receipt of a grant from the Mental Health Research Fund during part of the study.

\section{REFERENCES}

Eysenck, H. J. (1959). The Manual of the Maudsley Personality Inventory. University of London Press, London.

_- and Eysenck, S. B. G. (1964). Manual of the Eysenck Personality Inventory. University of London Press, London.

Goligher, J. C., Pulvertaft, C. N., and Watkinson, G. (1964). Controlled trial of vagotomy and gastro-enterostomy, vagotomy and antrectomy, and subtotal gastrectomy in elective treatment of duodenal ulcer. Brit. med. J., 1, 455-460.

Hathaway, S. R., and McKinley, J. C. (1951). Minnesota Multiphasic Personality Inventory. Manual revised 1951. The Psychological Corporation, New York.

Hollander, F. (1948). Laboratory procedures in the study of vagotomy (with particular reference to the insulin test). Gastroenterology, 11, 419-425.

Johnston, D., Goligher, J. C., and Duthie, H. L. (1966). Medical vagotomy: an assessment. Brit. med. J., 2, 1481-1485.

Kanter, V. B., and Hazelton, J. E. (1964). An attempt to measure some aspects of personality in young men with duodenal ulcer by means of questionnaires and a projective test. J. Psychosom. Res., 8, 297-309.

Kessel, N., and Munro, A. (1964). Epidemiological studies in psychosomatic medicine. Ibid., 8, 67-81.

Pascal, G. R., Thoroughman, J. C., Jarvis, J. R., and Jenkins, W. O. (1966). Early history variables in predicting surgical success for intractable duodenal ulcer patients. Psychosom. Med., 28, 207-215.

Roth, H. P. (1955). The peptic ulcer personality. Arch. intern. Med., 96, 32-43.

Sainsbury, P. (1960). Psychosomatic disorders and neurosis in outpatients attending a general hospital. J. Psychosom. Res. 4, 261-273.

Silverman, A. J., McGough, W. E., and Bogdonoff, M. D. (1967). Perceptual correlates of the physiological response to insulin. Psychosom. Med., 29, 252-264.

Sinclair-Gieben, A. H. C., Clark, C. G., Dean, A. C. B. (1962). Psychiatric illness following surgery for duodenal ulcer. Scot. med. J., 7, 168-172.

Thoroughman, J. C. (1963). Surgery and the patient with intractable peptic ulcer. Amer. J. Surg., 105, 334-337. 